\title{
Evaluation of experimental and numerical investigations into micro-hydroforming of platinum tubes for an industrial application
}

\author{
Christoph Hart ${ }^{1,}$, , Herwig Schiefer ${ }^{2}$, and Andreas Chlynin ${ }^{1}$ \\ 1 Cologne University of Applied Sciences, Betzdorfer Str. 2, 50679 Cologne, Germany \\ 2 Heraeus Precious Metals GmbH \& Co. KG, Heraeusstr. 12-14, 63450 Hanau, Germany
}

Received 10 April 2014 / Accepted 17 September 2014

\begin{abstract}
The presented results are based on an experimental feasibility study which was carried out for the application of micro-hydroforming in the manufacture of micro-sized products made from the material PtIr10. Within the scope of this product development, the prediction of feasible and failure-free expansions was one major aspect. This paper deals with the analysis of the failure cases which limited the expansions due to necking. The experimental investigations have shown a scattering of the forming results which was due to so-called size-effects resulting from the material grain structure. Simulations with the finite element method were used to determine the development of stresses and strains within the hydroformed tube. It was demonstrated that a superimposition of axial compressive stresses reduces the influence of size-effects and increases the feasible expansion diameter. Using these simulations, the applicability of an existing failure criterion to estimate a mean forming-limit was verified.
\end{abstract}

Key words: Micro-hydroforming, Platinum, Formability, Failure criterion, Size-effects

\section{Introduction}

Micro-hydroforming was developed as an innovative metal forming process to provide a technique for the economic mass production of complex hollow shaped components at microscale [1]. The forming process is based on the expansion of a starting tube by internal pressurization within a die cavity which corresponds to the final workpiece shape. Generally speaking, the process principle is along the same lines as the hydroforming of macro-components which is used extensively today in the mass-production of high-quality parts for automotive and sanitary applications [2]. However, besides occurring size-effects which have to be taken into account when forming metal materials at micro-scale $[3,4]$, the miniaturization of the process necessitates the consideration of new methods in the design in tools and sealing systems to ensure reliable production as well as sufficient product quality [5-7].

The requirement to manufacture miniaturized components in large quantities under cost-efficient conditions nowadays concerns numerous technology sectors [3]. In particular the medical market is characterized by the use of tubular microproducts which show great potential to be manufactured using

*e-mail: christoph.hartl@fh-koeln.de micro-hydroforming. Against this background, experimental feasibility studies were carried out into the application of this forming technology for the manufacture of appropriate products made from platinum materials. Within the scope of these investigations, the prediction of feasible and failure-free expansions was one major aspect. Failures which reduce the feasible expansion of metal tubes in hydroforming processes are due to the plastic instability of the tube material when necking is initiated with subsequent bursting [8]. When an additional axial compressive force is superimposed on the hydroformed tube, wrinkling and buckling can also occur [8].

Although there has been much research into the limits of hydroforming at macro-scale for a wide range of steel and aluminium materials (e.g. [9-14]), systematic research into this subject as regards micro-hydroforming has as yet only been carried out for stainless steel tubes with an outer diameter of $800 \mu \mathrm{m}$ and a wall thickness of $40 \mu \mathrm{m}$ [15-17]. Furthermore, until now no relevant findings have been published on macro or micro-scale hydroforming of platinum alloys.

The experimental bursting tests of micro-tubes and the comparison of the results with similar tests of macro-tubes in [15] have shown that size-effects have to be considered in micro-hydroforming, resulting in a reduction of possible expansion of about $50 \%$ for the steel material tested when 
scaling the process down to micro dimensions. The reason for this was provided with the work of $[16,17]$, where using a plain strain crystal plasticity finite element based modelling technique, it was theoretically predicted that localized necking of a micro-tube wall is related to the angle between the crystal slip systems and the hoop stress direction. Hence, as a result of the small number of grains in tube wall direction, necking and subsequent bursting progresses faster in the expansion of micro-tubes than in macro-tubes which can be regarded as a homogeneous continuum due to their larger number of grains.

With the objective of obtaining more detailed information about the influence of size-effects on the feasible expansions in micro-hydroforming processes of platinum tubes, results of an experimental product feasibility study were analysed regarding the occurrence of instabilities due to necking and bursting. The results of this analysis are described in the following sections, complemented by numerical investigations into the applicability of a criterion to predict failure occurrence.

\section{Experiments}

Figure 1 shows the schematic set up of the microhydroforming tool for the experimental feasibility study. This tool consisted of two forming dies where one of the dies (Figure 1 on the left) was mounted to be movable in the direction of the second die (Figure 1 on the right). Furthermore, the movable forming die was equipped with the inlet for the pressurizing medium. Water was used in this case as a pressurizing fluid. This set up enabled an expansion of the starting tubes due to the controlled application of an internal pressure $p_{\mathrm{i}}$ and a superimposed axial force $F_{\mathrm{a}}$, generated by the controlled axial stroke $u_{\mathrm{z}}$.

To apply these forming loads, the tool was integrated into the micro-hydroforming machine system shown in Figure 2. This system was designed for research into the massproduction of micro-components using hydroforming processes [1, 5-7]. It is applicable for the micro-hydroforming of components with cross section dimensions between about 200 and $2000 \mu \mathrm{m}$ and is equipped with a spindle driven pressure intensifier which enables an internal pressure $p_{\mathrm{i}}$ of up to $400 \mathrm{MPa}$ to be applied. The machine system is provided with three axes for a translatory movement of tool elements: two linear actuators with spindle gears with a maximum force $F_{\mathrm{a}}$ of $800 \mathrm{~N}$, and one hydraulically driven actuator with a maximum force $F_{\mathrm{c}}$ of $20 \mathrm{kN}$. For the experiments described here, one of the linear actuators with spindle gear was used to achieve the movement of the forming die with the force $F_{\text {a }}$. The hydraulic drive was applied during the calibration of the formed components under increasing internal pressure and locking the two forming dies against each other at the moment when these came into contact. The devices for generating hydraulic pressure and forming medium pressure are integrated within the machine housing. The machine is equipped with a flexible control system based on a conventional programmable logic controller system. It enables also forces, pressures and strokes to be measured and to be recorded during the forming process.

To ensure a reliable sealing of the tubular workpieces during the forming process, two proven concepts generally used in

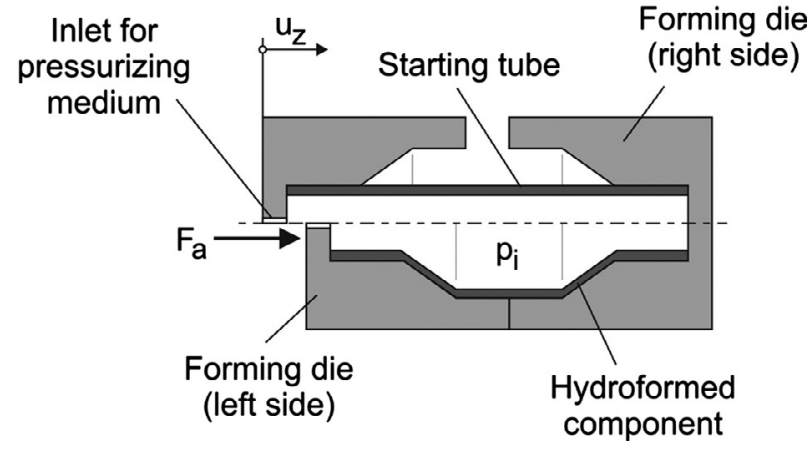

Figure 1. Micro-hydroforming tool (schematic).

the practical application of conventional hydroforming [6] were scaled down (see Figure 3). The concept depicted in Figure $3 \mathrm{a}$ was applied to conduct expansion tests without an axial movement of the tube ends. The basic principle of this concept lies in a local forming of the tube end with a conical sealing element and the use of this to close the pressurized workpiece with a force $F_{\mathrm{d}}$ during the forming process.

The concept shown in Figure $3 b$ was used for the experiments with an axial movement of the tube ends. With this concept the sealing occurred predominantly due to a sharp edge surrounding the contact area between tool and tube front. This edge was pressed into the tube front and thereby enabled the sealing. Additionally, a short cylindrical part of the die, located inside the tube end, created a defined gap which reduced the wall thickness by a few microns when it was inserted and thereby ensured an additional sealing around the contact areas between the tube end, surrounding die and the inserted cylindrical die element. This concept was tested with internal pressures of up to $120 \mathrm{MPa}$ where it still provided a reliable sealing. However, it has to be mentioned that the experiments were carried out with selected tubes from one production batch, showing uniform dimensions without the influence of variations which can arise for example from batch changes in mass-production. It is expected that such variations in tube diameter and tube wall thickness respectively, could affect the performance in sealing when implementing this concept.

The starting tubes used consisted of the platinum alloy PtIr10 in annealed condition with the dimensions and mechanical specifications determined by tensile tests of the tubular material as listed in Table 1.

Two types of process load applications were considered in this study: the first type with only the internal pressure $p_{\mathrm{i}}$ as a forming load for the expansion and with the tube ends fixed by the sealing system; and a second, with expansion by the internal pressure $p_{\mathrm{i}}$ and an axial compressive force $F_{\mathrm{a}}$, caused by an axial stroke $u_{\mathrm{z}}$ of the left half of the tool as can be seen in Figure 1. Figure 4 represents the load paths for the two types of process controls. For both types, the internal pressure $p_{\mathrm{i}}$ was constantly increased during the tests by $12 \mathrm{MPa}$ per second. The experiments with this first load path, where solely pressurization was applied, were conducted at the beginning of the product feasibility study, in order to obtain information about the pressure which induces necking and 

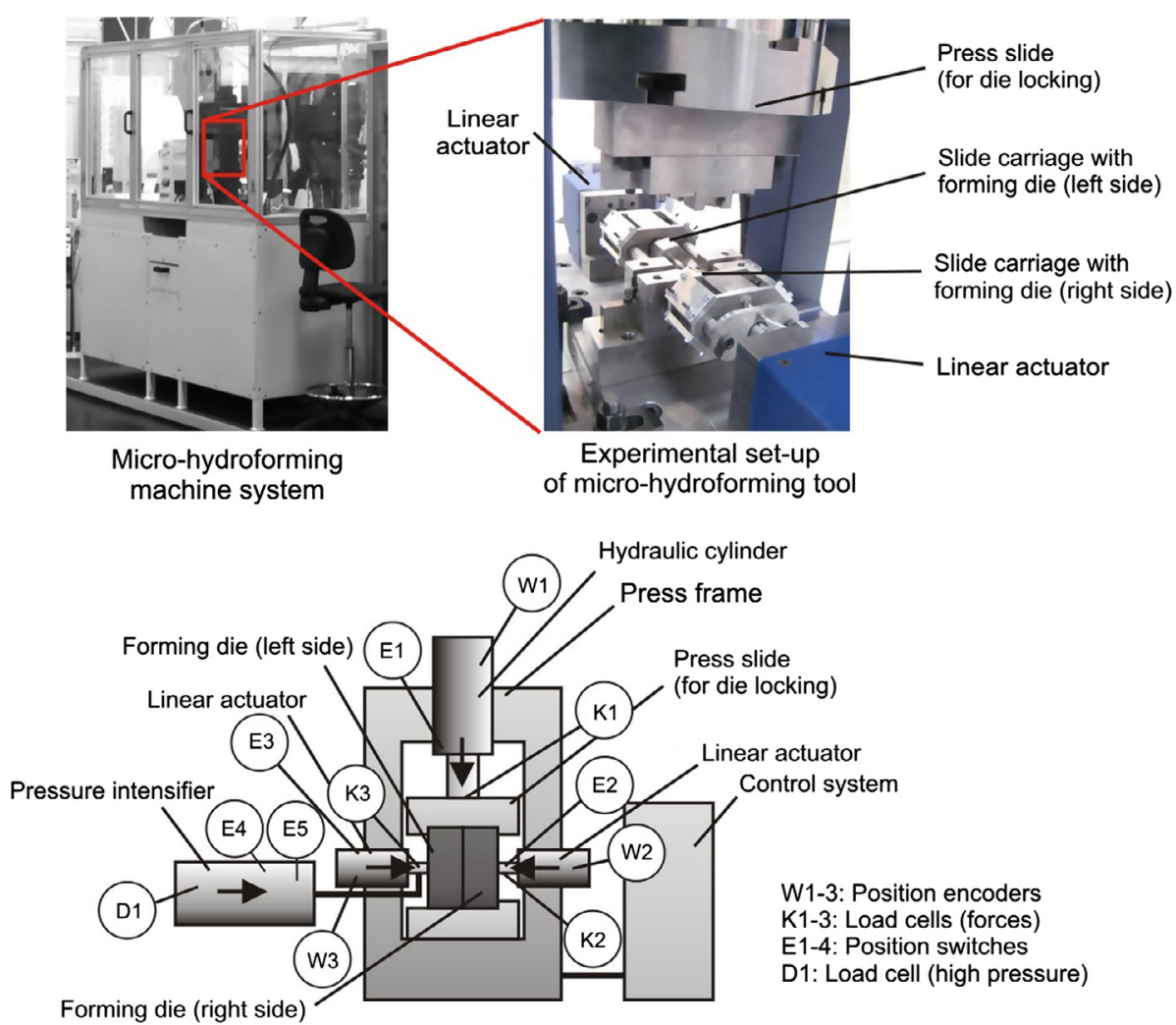

Schematic view of machine functions

Figure 2. Set-up and functions of the micro-hydroforming machine system.

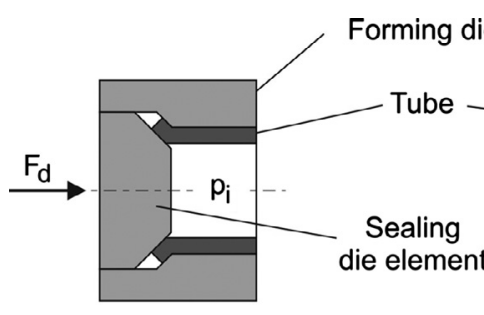

(a)

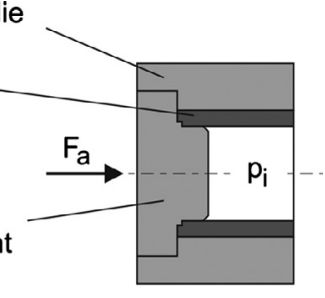

(b)

Figure 3. Detail of the forming tool with the used sealing principles (a) rigid clamping of the tube end, (b) moveable tube end.

Table 1. Material properties of PtIr10 and dimensions of the hydroformed micro-tubes.

\begin{tabular}{ll}
\hline Elastic modulus $E$ & $202300 \mathrm{MPa}$ \\
Poisson's ratio $v$ & 0.378 \\
Initial yield stress $\sigma_{\mathrm{Y} 0}$ & $250 \mathrm{MPa}$ \\
Tensile strength $\sigma_{\mathrm{UTS}}$ & $346 \mathrm{MPa}$ \\
Tube outer diameter $d_{0}$ & $1651 \mu \mathrm{m}$ \\
Tube wall thickness $t_{0}$ & $76 \mu \mathrm{m}$ \\
Tube length $l_{0}$ & $8000 \mu \mathrm{m}$ \\
\hline
\end{tabular}

subsequent bursting of the tube wall. The second load path was part of the process control to form the final products, which included an additional calibration of the formed components by raising the internal pressure $p_{\mathrm{i}}$ to $120 \mathrm{MPa}$.

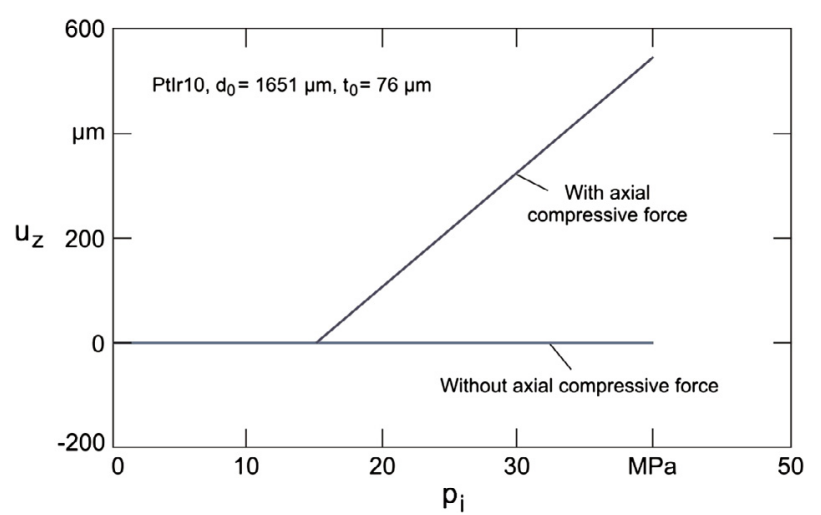

Figure 4. Load paths of the analysed tests.

For this second load path the values for $p_{\mathrm{i}}$ and $u_{\mathrm{z}}$ were determined in a first step according to the fundamentals for hydroforming process design provided in [18], using the specifications of the tube material as presented in Table 1 . Based on this, and supported by finite element simulations, the load path was then optimized by conducting systematic tests varying the respective values. It was found out that the appropriate level of internal pressure $p_{\mathrm{i}}$ to initiate plastic yielding of the tube material was around $15 \mathrm{MPa}$, superimposed with an axial force $F_{\mathrm{a}}$ of about $81 \mathrm{~N}$ due to the start of the tool movement with the axial stroke $u_{\mathrm{z}}$. For $u_{\mathrm{z}}$ it was determined that a ratio of increase of $u_{z} / p_{\mathrm{i}}=22 \mu \mathrm{m} / \mathrm{MPa}$ enabled the 


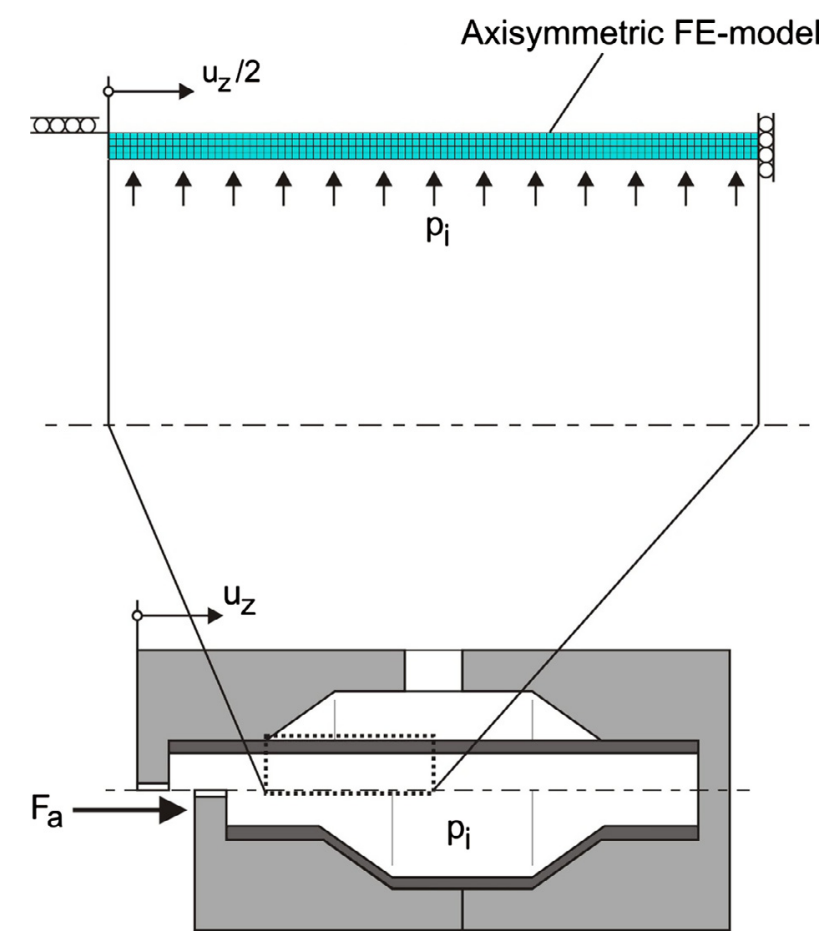

Figure 5. Diagram of the developed model for FE-simulations.

forming of the components with an internal pressure $p_{\mathrm{i}}$ of around $34 \mathrm{MPa}$ before the final calibration step.

\section{Simulations}

A two dimensional, axisymmetric simulation model was developed to assist the analysis of the experimental results as shown in Figure 5. The software ABAQUS with an explicit algorithm was applied to compute the finite element based simulation model which consisted of about 400 elements. Fournode, linear, axisymmetric elements of the type CAX4R were used. The symmetry of the forming process made it possible to simplify the model and to only calculate one half of the formed component. Furthermore, the part of the tube end located in the tool area where the die cavity dimension corresponds to the outer tube diameter was neglected and not included in the model. This was considered to be admissible, as in this area no notable change in the wall thickness was measured in the experimentally formed components. Therefore, material movement and relative movement between the outer surface of the tube end and the tool surface in this area were negligible in these experiments.

The internal pressure $p_{\mathrm{i}}$ was applied as a normal stress to the inner surface of the tube model and the axial stroke $u_{\mathrm{z}}$ was implemented by the appropriate displacement of the outer element nodes in the sectional plane of the model as depicted in Figure 5. To reproduce the movement of the formed component at the selected sectional planes of the model, geometrical boundary conditions for the element nodes within these planes were utilized as illustrated in Figure 5. For the simulations without axial compression force, an axial stroke of $u_{\mathrm{z}}=0$ was selected.

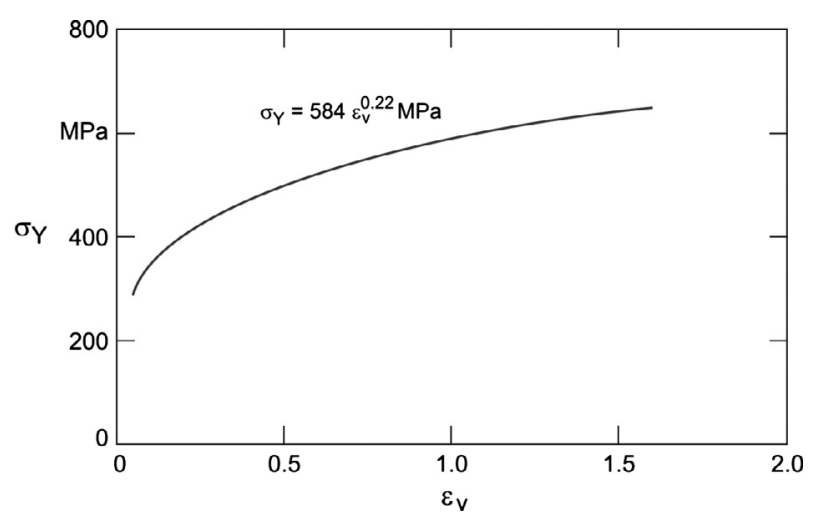

Figure 6. Approximated yield curve for the material PtIr10.

In order to establish the ideal forming process without sizeeffects, homogenous and isotropic elastic-plastic material behaviour with strain hardening was applied, according to the material properties presented in Table 1 and with the yield curve of the tube material PtIr10 as provided in reference [19]. According to reference [19], upsetting tests of cylindrical specimens were conducted to determine the yield curve which was approximated in the research described here with $\sigma_{\mathrm{Y}}=584 \varepsilon_{\mathrm{V}}^{0.22} \mathrm{MPa}$, with the yield stress $\sigma_{\mathrm{Y}}$ and the plastic equivalent strain $\varepsilon_{\mathrm{v}}$, as shown in Figure 6.

Furthermore, the simulation model was used to determine the significance of a ductile fracture criterion developed by [20], which was successfully applied in [21] to predict the initiation of necking and bursting in hydroforming of macro-tubes made from stainless steel. According to [20], ductile fracture within a homogenous, isotropic material occurs when the maximum damage value exceeds a critical value $C$, with:

$$
C=\int_{0}^{\varepsilon_{\mathrm{vf}}} \frac{2 \sigma_{1}}{3\left(\sigma_{1}-\sigma_{\mathrm{m}}\right)} \mathrm{d} \varepsilon_{\mathrm{v}}
$$

where $\sigma_{1}$ is the maximum principal stress, $\sigma_{\mathrm{m}}$ the hydrostatic stress, $\varepsilon_{\mathrm{v}}$ the equivalent plastic strain and $\varepsilon_{\mathrm{vf}}$ the equivalent plastic strain at occurrence of instability. The calculation of this damage value was implemented into the analysis tools of the simulation software to provide an appropriate distribution of $C$ for the entire workpiece within the individual calculation steps.

\section{Results}

From a total number of approximately 300 experimental trials, conducted within the frame of the feasibility study mentioned above, those tests were analysed which showed failures due to necking and bursting of the tube wall. Figure 7 summarizes these experiments, the results having been divided into the two groups of different load paths and listed in ascending order of the measured bursting pressure $p_{\mathrm{iB}}$. A comparatively high degree of scattering was detected for the internal pressure at the occurrence of bursting, in particular for the experiments conducted without axial compressive force. For these tests, the lowest value of $p_{\mathrm{iB}}$ was determined with $11 \mathrm{MPa}$, and the highest with $39 \mathrm{MPa}$. The bursting pressures for the trials with axial compressive force $F_{\mathrm{a}}$ were between 32 and $39 \mathrm{MPa}$. 


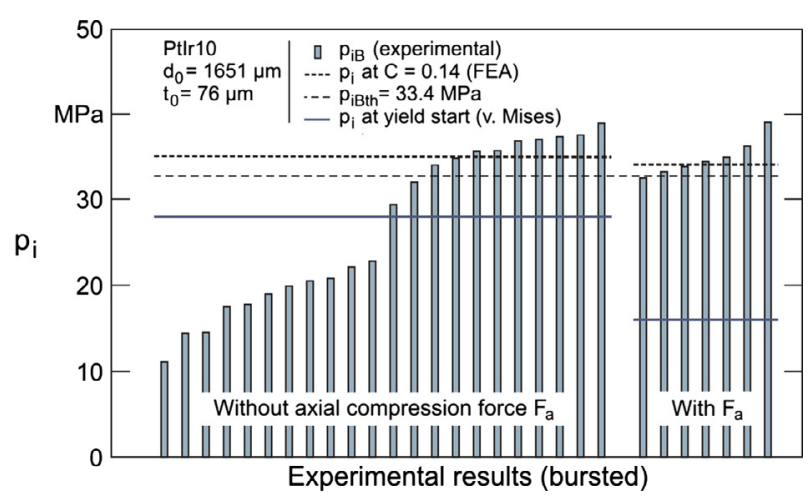

Figure 7. Measured bursting pressures and predicted pressures for initiation of necking and yield start.

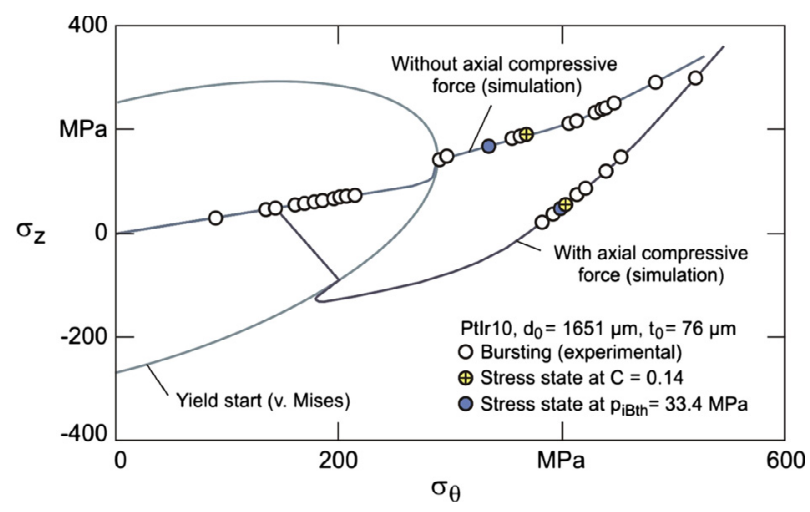

Figure 8. Simulation of theoretical stress states at fracture for the tube expansions with and without axial compressive force.

To obtain more detailed information about the acting stress state at fracture, the experimentally used load paths shown in Figure 4 were applied to the simulation model described above. Figure 8 shows the calculated development of the hoop stress $\sigma_{\theta}$ and the axial stress $\sigma_{\mathrm{z}}$ at the point of maximum expansion of the tube wall, with the experimental results at the occurrence of failures transferred to the stress curves, and complemented by the theoretical yield start of the tube according to von Mises. To transfer the experimental results to these curves, the simulated stresses $\sigma_{\theta}$ and $\sigma_{\mathrm{z}}$ at the point where the simulations reached the experimentally determined internal pressures $p_{\mathrm{i}}$ for the occurrence of a failure (according to Figure 7) were collected and marked in the diagram in Figure 8.

The comparison of the simulated stress states and experimental occurrence of failures shows two important aspects: (a) a considerable number of failures took place before the theoretical yield start of the tube material when no axial compressive force was applied; this is also evident in Figure 7 where the calculated internal pressure at yield start is indicated, and (b) in the case of superimposed axial compressive force, failures appeared only after the point where the resulting axial stress $\sigma_{\mathrm{z}}$ within the tube wall changed from compressive stress to tensile stress.

It can be reasonably assumed that the premature bursting before the theoretical yield start of the expanded tubes was caused by the effect described in $[16,17]$ which results from

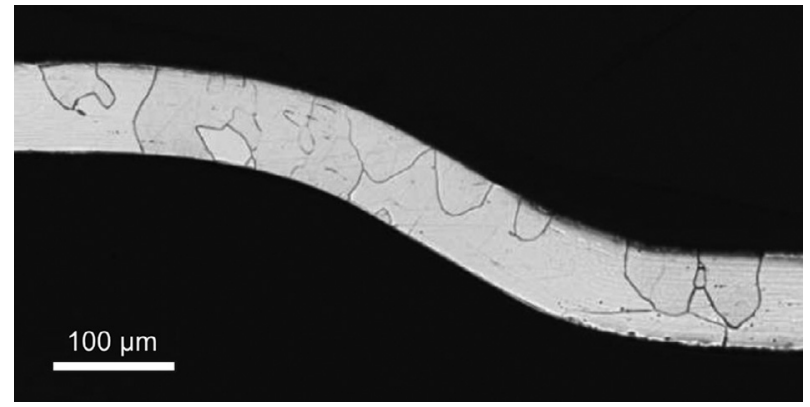

Figure 9. Microstructure of a formed tube wall.

a comparatively large ratio of material grain size to wall thickness $d_{\mathrm{k}} / t_{0}$. In cases where single huge grains are oriented with their crystal slip systems to the hoop stress direction in such a way that the resulting shear stress to move the lattice planes against each other is smaller than the respective shear stress of adjacent grains, local necking and subsequent bursting occur earlier in comparison with homogenous macro-tubes with a larger number of grains. In order to verify this assumption, the microstructure of the tubes was analysed. Figure 9 shows a cross section in longitudinal direction of a formed component with the initial tube wall thickness on the right and the expanded tube wall on the left. This figure illustrates that single grains cross the tube wall thickness which contributes to the described size-effect.

The second determined aspect, which shows that a superimposed compressive force improves the formability of the tube metal material and reduces the occurrence of instabilities due to necking, has already been identified for conventional tube hydroforming, e.g. [8, 18]. The fact that size-effects due to the large ratio of grain size to tube wall thickness increase the danger of premature necking and bursting, and that none of these failures was determined for the investigated samples within the area of $\sigma_{\mathrm{z}}<0$, leads to the recommendation, that a superimposed axial compressive force should be applied in micro-hydroforming of a maximum feasible amount within the limits of wrinkling and buckling of the tube wall.

Against the background of evaluating a criterion to predetermine the feasibility of micro-hydroforming processes with numerical simulation, the application of the fracture criterion according to equation (1) was investigated in more detail. To determine the critical value $C$, the mean expansion diameter at the occurrence of bursting was measured for the hydroformed specimens formed without axial compressive force. To exclude a decisive influence of size-effects, only these cases were considered which showed fracture above the theoretically determined yielding of the tubes. An average expansion ratio of $\left(d_{1 \mathrm{~B}}-d_{0}\right) / d_{0}=0.09$ was determined for these tubes at the occurrence of fracture, where $d_{0}$ is the initial outer tube diameter and $d_{1 \mathrm{~B}}$ the mean value of the attained maximum expansion diameter at bursting. The simulation delivered a critical value for this expansion ratio of $C=0.14$.

This critical value was applied to the simulation model with axial compressive force. Figures 10 and 11 show the distribution of the calculated equivalent plastic strain $\varepsilon_{\mathrm{v}}$ and of the $C$-value for the two simulations when a maximum value $C$ of 


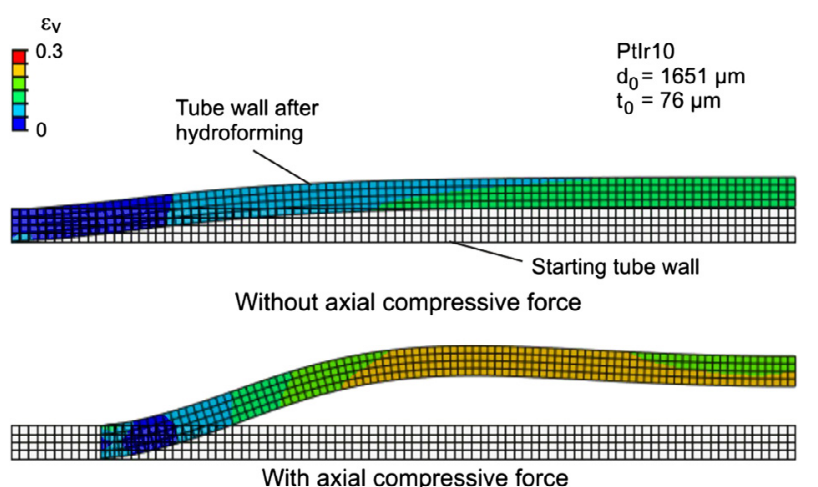

Figure 10. Simulation result of plastic equivalent strain at maximum value $C=0.14$.

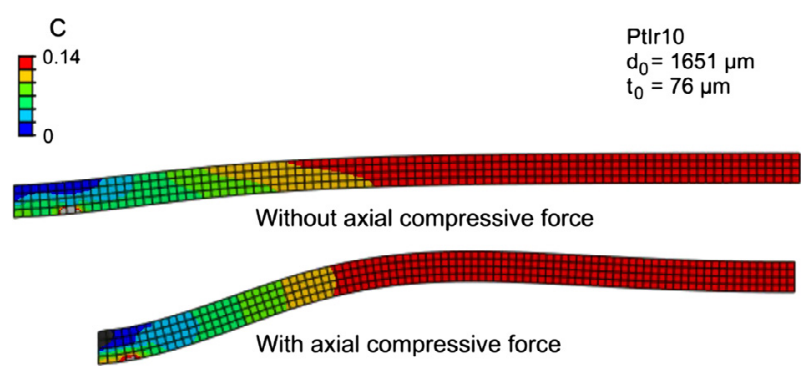

Figure 11. Distribution of the value $C$ when a maximum value of 0.14 is reached.

0.14 was reached. The application of this damage value to the simulation with axial compressive force $F_{\mathrm{a}}$ revealed an expansion ratio at the occurrence of failures of $\left(d_{1 \mathrm{~B}}-d_{0}\right) /$ $d_{0}=0.201$. In the experimental tests, an average expansion ratio of 0.193 at the initiation of necking and bursting was determined. This corresponds to a deviation of about $4 \%$ between calculated and experimentally determined occurrence of failures which shows a comparatively good applicability of this damage criterion in order to estimate a mean forminglimit.

The calculated values of the maximum internal pressures at the critical value $C$ of 0.14 were $35 \mathrm{MPa}$ for the expansion without superimposed axial compressive force $F_{\mathrm{a}}$, and 34.1 MPa for the expansion with $F_{\mathrm{a}}$. Both levels of these maximum theoretically determined pressures are comparatively close to the mean values of bursting pressures measured with the experimental tests when the failure cases are not taken into consideration which occurred below the yield start of the pressurized tubes. This also becomes evident in Figure 7. For the experiments, the determined mean values of bursting pressures were $35.4 \mathrm{MPa}$ without axial compression force $F_{\mathrm{a}}$ and $34.9 \mathrm{MPa}$ with axial compression by $F_{\mathrm{a}}$. However, this high prediction accuracy for the onset of instabilities in the case of the tests without $F_{\mathrm{a}}$ is due to the fact that the mean value of the formed maximum expansion diameters at occurrence of failures was taken from these tests as the basis to determine the critical value of $C$ and that failures which occurred below the yield pressure were not considered. As far as hydroforming tests with superimposed axial force $F_{\mathrm{a}}$ are concerned, the prediction accuracy is supported by the reduced scattering of the experimental results compared to the forming without $F_{\mathrm{a}}$, which is caused by the superimposed compression stresses as discussed above. The bursting pressures of the experiments without $F_{\mathrm{a}}$ and above the yield start deliver a standard deviation of $2.7 \mathrm{MPa}$ whereas the experiments with $F_{\mathrm{a}}$ result in a standard deviation of $2.2 \mathrm{MPa}$.

It should be noted that the values and parameters compared here between simulated and experimental results are mean values and that the mentioned scattering of the material behaviour remains unconsidered. The comparatively good congruence of the simulation and the experiment is also due to the fact that, even though the yield curve was taken from macro-sized specimens, the computed plastic strains were relatively small and the initial yield stress $\sigma_{\mathrm{Y} 0}$ used in the simulations was obtained by tensile tests from the original tubes. The distribution of the equivalent plastic strain $\varepsilon_{\mathrm{v}}$, depicted in Figure 10, shows maximum values of $\varepsilon_{v}$, below about 0.25 .

The positions of the initiation of failures calculated with this damage criterion are also depicted in the Figures 7 and 8 to enable a comparison with the theoretical bursting pressure $p_{\mathrm{iBth}}$ which is often used as a criterion for the limit of hydroforming processes under free expansion without contact to a surrounding tool. Applying the common correlation to estimate $p_{\text {iBth }}$ of a pressurized tube according to [18] to the specimens used here with the specifications as summarized in Table 1, this theoretical bursting pressure $p_{\mathrm{iBth}}$ is $33.4 \mathrm{MPa}$. This corresponds to a difference of about $4 \%$ respectively $6 \%$ to the experimentally determined mean values of pressures in the event of bursting for the tests with and without $F_{\mathrm{a}}$. This compares with a difference of less than about $2 \%$ between the experimental determined bursting pressures and the internal pressures at occurrence of instabilities determined using the conducted simulations.

\section{Conclusions}

In this work, the occurrence of failures caused by localised necking and following bursting in micro-hydroforming of platinum tubes was investigated. Load paths for the hydroforming of the specimens were applied taking into account both forming with and without a superimposed axial compression force. In both cases, the measured values of the internal pressures in the event of instabilities showed a distinct scattering, with however a reduced deviation between the individual test results for the hydroforming with a superimposed axial force. Furthermore, the application of an axial compression force avoided the premature bursting of the formed tubes below the theoretical yield limit, which was detected for a considerable number of the expansion tests without axial force. Additionally, the feasible expansion diameter was increased by the use of a superimposed axial compression. With the aid of finite element simulations it was found that, within the frame of the investigated process parameters and number of specimens, no failures occurred as long as axial compressive stresses were acting within the formed tube wall. An analysis of the microstructure of the tube material used showed a comparatively high ratio of material grain size to the tube wall thickness. It was concluded 
that the scattering of the measured internal pressure at the occurrence of failures can be attributed to the size-effects resulting from the amount of this ratio. It is evident that further research in thermo-mechanical treatment strategies for finer grain sized micro-tube materials, while still allowing for sufficient formability is necessary.

The developed finite element model in this work, with the implemented ductile fracture criterion applied to the investigated experiments, has proved to be suitable to predict a feasible expansion of micro-tubes as a mean value. However, to obtain a simulation model which enables the determination of the scattering of the forming results observed here, both the determination of yield curves, as a basis for forming simulations, and the applied fracture criteria should consider possible size-effects caused by the microstructure of the tube material. In this research, the yield curve data were taken from upsetting tests of specimens at macro-size, due to the absence of suitable test methods at micro-part dimensions. Within the conducted product development work, from which the results presented here accrued, it was noted that demand remains for additional research and development work. Improved failure criteria could be built on simulation models which consider random distribution and size of grains as developed by $[16$, 17] and are then applied to a certain range of simulations with statistical grain distribution, to cover the possible field along the load path where instabilities could occur.

In spite of the fact that the micro-hydroforming process has proven to be suitable for the manufacture of complex shaped components which are required for example by the medical industry, further research is still needed before serial production is possible.

\section{References}

1. C. Hartl, G. Anysodor, in Proceedings of Int. Conf. Metal Forming 2010, Toyohashi (2010).

2. C. Hartl, J. Mater. Process. Technol. 167 (2005) 383-392.
3. Y. Qin, A. Brockett, Y. Ma, J. Zhao, C. Harrison, W. Pan, X. Dai, D. Loziak, Int. J. Adv. Manuf. Technol. 47 (2010) 821-837.

4. F. Vollertsen, D. Biermann, H.H. Hansen, I.S. Jawahir, K. Kuzman, CIRP Annals 58 (2009) 566-587.

5. C. Hartl, G. Anyasodor, in Proceedings of Lamdamap $9^{\text {th }}$ Int. Conf., London, 2009.

6. C. Hartl, Micro-Hydroforming, in Micro-Manufacturing Engineering and Technology, edited by Y. Qin (Elsevier, Amsterdam, 2010).

7. C. Hartl, G. Anyasodor, T. Ptaschlik, J. Lungershausen, S. Lippert, Int. J. Adv. Manuf. Technol. 47 (2010) 853-858.

8. F. Dohmann, in Umformtechnik, edited by K. Lange, vol. 4 (Springer, Berlin, 1993)

9. M. Koç, T. Altan, Int. J. Mach. Tools Manuf. 42 (2002) 123-138.

10. D.E. Green, in Proceedings of Int. Conf. Hydroforming, Stuttgart (2003) 299-314.

11. M. Sorine, C.H.M. Simha, I.V. Riemsdijk, M.J. Worswick, Int. J. Mech. Sci. 50 (2008) 1411-1422.

12. Z. Xia, 2001, ASME J. Eng. Mater. Technol. 123 (2001).

13. M. Jansson, L. Nilsson, K. Simonsson, J. Mater. Process. Technol. 195 (2008) 3-14.

14. Y.M. Hwang, Y.-K. Lin, H.-C. Chuang, J. Mater. Process. Technol. 209 (2009) 5024-5034.

15. C. Hartl, G. Anyasodor, J. Lungershausen, in Proceedings of Int. ESAFORM Conf. Metal Forming 2011, Belfast (2011)

16. W. Zhuang, S. Wang, J. Lin, D. Balint, C. Hartl, Europ. J. Mechanics A/Solids 31 (2011).

17. W. Zhuang, S. Wang, J. Cao, J. Lin, C. Hartl, Int. J. Adv. Manuf. Technol. 47 (2009), 859-865.

18. C. Hartl, in Hydroforming for advanced manufacturing, edited by M. Koc (Woodhead Publishing, Cambridge, 2008).

19. N.N., VDI-Standard 3200, Issue 3 (The Association of German Engineers, Beuth, Berlin, 1982).

20. P. Brozzo, B. Deluka, R. Rendina, in Proceedings of $7^{\text {th }}$ Biannual Congr., IDDRG, Amsterdam, 1972.

21. M. Saboori, J. Gholipour, H. Champliaud, J. Savoie, P. Wanjara, in Proceedings of Int. ESAFORM Conf. Metal Forming 2011, Belfast, 2011.

Cite this article as: Hartl C, Schiefer H \& Chlynin A: Evaluation of experimental and numerical investigations into micro-hydroforming of platinum tubes for an industrial application. Manufacturing Rev. 2014, 1, 17. 